\title{
ELECTRICAL DEVELOPMENT IN SPINAL CORD CELL CULTURE
}

\author{
MEYER B. JACKSON, ${ }^{* 1}$ HAROLD LECAR,* DOUGLAS E. BRENNEMAN, $\$ \S$ \\ SANDRA FITZGERALD $\ddagger$ AND PHILIP G. NELSON $\ddagger$
}

* Laboratory of Biophysics, Intramural Research Program, National Institute of Neurological and Communicative Disorders and Stroke, $\ddagger$ Laboratory of Developmental Neurobiology, Intramural Research Program, National Institute of Child Health and Human Development, and §Pharmacology Research Associate Program, National Institute of General Medical Sciences, National Institutes of Health, Bethesda, Maryland 20205

Received December 28, 1981; Revised February 11, 1982; Accepted March 23, 1982

\begin{abstract}
Parallel electrophysiological and neurochemical studies of development are reported for mouse spinal cord cell cultures. The time course of electrical activity and the stage-dependent effects of tetrodotoxin on levels of the neuronal enzyme choline acetyltransferase were compared to establish the presence of spontaneous electrical activity at a time when tetrodotoxin adversely affects development. The extracellular patch electrode makes it possible to examine the ongoing electrical activity of the small cells present in young cultures. A rapid increase in spontaneous electrical activity during the first 2 weeks in culture was found to correlate closely with the onset of tetrodotoxin-induced depression of choline acetyltransferase activity, supporting the idea that ongoing electrical activity plays a role in neuronal development.

The development of inhibitory synaptic activity occurs gradually throughout the period of culture, whereas excitatory synaptic activity and action potentials develop in unison, reaching maximal levels during the 2nd week in culture. For all cultures tested, ranging in age from 9 to 45 days old, acute bath application of $\gamma$-aminobutyric acid (GABA) abolished spontaneous electrical activity. Glycine is relatively ineffective in abolishing spontaneous activity in young cultures which have few inhibitory postsynaptic potentials (IPSPs), but glycine becomes as effective as GABA at a later stage of development. This suggests rather different timetables of development for GABA and glycine receptors, with glycine receptors developing in parallel with IPSPs.
\end{abstract}

The dissociation and culture of embryonic mouse spinal cord yields cells that develop in vitro, producing elaborate neuronal processes. This morphological development is accompanied by the development of electrical excitability and chemical synapses, leading to vigorous spontaneous electrical activity (Ransom et al., 1977). The morphological progress of these cultures can be observed at any stage of development by light and electron microscopy, but to date, electrophysiological studies using microelectrodes have been feasible only for the larger cells found in older cultures. Spinal neurons which have been growing in culture for less than 20 days are too small for reliable intracellular recordings. As a result, the electrical development which accompanies the morphological development cannot be followed.

Interference with electrical activity produced by the selective sodium channel blocker tetrodotoxin (TTX) has been shown to create deficits in neuronal development

\footnotetext{
${ }^{1}$ To whom correspondence should be addressed at Department of Biology, University of California, 405 Hilgard Avenue, Los Angeles, CA 90024.
}

as indicated by a decrease in the number of surviving large spinal cord neurons (Bergey et al., 1981a). This apparent role of electrical activity in normal neural development has heightened our curiosity as to the existence and nature of spontaneously occurring electrical activity in young spinal cultures. In an effort to examine the stage dependence of the requirement for electrical activity with greater temporal resolution, we have made use of the neuronal enzyme choline acetyltransferase (CAT) (Godfrey et al., 1980) as a biochemical assay of neuronal development.

When an intracellular microelectrode impales a small cell, membrane damage alters the cell's electrical characteristics. The damage is variable and strongly dependent on cell size, but it precludes many kinds of careful experimentation with cells having diameters less than about $20 \mu \mathrm{m}$. Extracellular recording is less damaging but generally is considered to be less sensitive. With the patch electrode, much improved extracellular recording of electrical signals is possible. Very sensitive patch electrode techniques were introduced originally to record the electrical current through single ionic channels in the 
plasma membranes of intact cells (Hamill et al., 1981; Neher et al., 1978). These techniques have been applied successfully to the recording of single channel currents in tissue culture (Jackson and Lecar, 1979; Nelson and Sachs, 1979; Jackson et al., 1982). The same techniques also can be used to record spontaneous electrical events in cells as small as $5 \mu \mathrm{m}$ without penetration and damage. In this study, the patch electrode technique was used to monitor the electrophysiological changes that occur during the development of spinal cord cell cultures. Parallel studies of choline acetyltransferase in the absence and presence of TTX were made during the same early stages to ascertain the developmental role of early electrical activity.

\section{Materials and Methods}

Cell cultures were prepared by dissociating spinal cords removed from 12-day mouse embryos following the procedures of Ransom et al. (1977). The cells attached to collagen-coated plastic dishes and could be examined the same day.

Al various times after plating, cells in $35-\mathrm{mm}$ dishes were washed and bathed in Earle's saline buffered at $\mathrm{pH}$ 7.4 with $20 \mathrm{~mm}$ HEPES. The culture dishes were placed on the stage of an inverted phase contrast microscope and viewed at a magnification of $\times 200$. The temperature was maintained at 35 to $37^{\circ} \mathrm{C}$ with a thermoelectric regulator. The aqueous surface was covered with oil to prevent evaporation.

Patch electrodes were fabricated in a microforge (Neher et al., 1978). The fire-polished electrode tips had inner diameters of about 1 to $2 \mu \mathrm{m}$. They were filled with the bathing medium and had resistances ranging from 2 to 5 megohms. When a patch electrode is pressed against the cell surface, the apparent electrode resistance increases by 3 - to 10 -fold. Gentle suction applied through the electrode appreciably increases the resistance of the seal between the electrode wall and the membrane, with final values ranging from 20 to above 40 megohms.

Currents through the patch of membrane under the electrode tip were recorded with a current-to-voltage converter similar to that used for single channel recording (Neher et al., 1978). The amplifier output was $50 \mathrm{mV}$ per 1-pA input. The bandwidth was always $2 \mathrm{kHz}$ or greater, and the base line noise level was generally less than $1 \mathrm{pA}$ peak to peak, referred to input.

Intracellular recordings were made with 40 - to 80megohm glass microelectrodes filled with either $3 \mathrm{M} \mathrm{KCl}$ or $4 \mathrm{M}$ potassium acetate.

In a typical experiment, 10 to 25 cells were examined. Patch electrode recordings were maintained for at least $3 \mathrm{~min}$. All activity observed was spontaneous. Note was made for each cell as to the presence of spontaneously occurring action potentials, excitatory postsynaptic potentials (EPSPs), and inhibitory postsynaptic potentials (IPSPs). No attempt was made to measure the frequency of any type of event in any given cell.

Neurons could be recognized by their appearance (Ransom et al., 1977). Even in very young cultures, it was possible to distinguish dorsal root ganglion cells from spinal cord cells. In general, cells of varying size and morphology were examined. The average diameter of a cell soma was estimated visually with a calibrated graticule.

Appropriate volumes of $10 \mathrm{~mm}$ glycine or $10 \mathrm{~mm}$ GABA ( $\gamma$-aminobutyric acid) were added to some of the cultures following the initial characterization of their activity. The final GABA or glycine concentration was $0.4 \mathrm{~mm}$. In many cases, the patch electrode recording from a cell was maintained during the addition of these substances.

Cultures identical to those used in electrophysiological studies were divided into two groups with $1 \mu \mathrm{M}$ TTX added to the culture medium of one of the groups for various periods of time. CAT activity was assayed in both groups by a modification of a previously described method (Godfrey et al., 1980; Schrier et al., 1974). The cultures were washed three times with phosphatebuffered saline; the cells then were disrupted during a 30 min incubation in a buffered solution which consisted of the following: $50 \mathrm{~mm} \mathrm{KPO}_{4}, \mathrm{pH} 6.8,1 \mathrm{~mm}$ potassium EDTA, $0.125 \%$ Triton X-100, and $0.2 \mathrm{M} \mathrm{NaCl}$. The CAT activity in each vessel was measured with a reaction mixture which contained $0.10 \mu \mathrm{Ci}(1$ to $14 \mathrm{C})$ of acetylcoenzyme A (New England Nuclear), $0.2 \mathrm{~mm}$ acetylcuenzyme A, $4 \mathrm{~mm}$ choline chloride, and $0.1 \mathrm{~mm}$ neostigmine bromide. Fnzyme activity was measured during 10-min incubations at $37^{\circ} \mathrm{C}$. The reaction was terminated by the addition of $1 \mathrm{ml}$ of cold phosphate buffer and the radioactive product was isolated by anion exchange columns.

The assay was performed with a saturating concentration of substrate so that the extent of the reaction was linear in time and in cell concentration; backgrounds were 10 pmole. The in situ assay described above gave values which were $15 \%$ to $20 \%$ greater than those obtained from homogenates scraped from companion cultures grown in $35-\mathrm{mm}$ dishes. A specific CAT inhibitor has been shown to eliminate $85 \%$ of the activity (Godfrey et al., 1980; Schrier et al., 1974).

\section{Results}

Patch electrode recordings. With the patch electrode, recordings were made of spontaneous electrical events in cells as small as $5 \mu \mathrm{m}$. In order to identify the events observed, intracellular voltage was recorded with a potassium acetate-filled microelectrode, and a patch electrode recording was performed simultaneously. This control was necessarily done on large cells from well developed older cultures. Action potentials, EPSPs, and IPSPs seen with the intracellular electrode were always accompanied by corresponding signals in the patch electrode (Fig. 1). The signals recorded by the patch electrode were clearly different from the signals seen during intracellular voltage recording, with consistent and characteristic distortions. For example, action potentials always appeared as large biphasic signals in the patch electrode. Since the amplifier was designed to record picoampere currents, action potentials often saturated the output (range, \pm 300 $\mathrm{pA}$ ) if the bandwidth was extended beyond 1 to $2 \mathrm{kHz}$. EPSPs and IPSPs produced small monophasic deflections in the appropriate direction.

A comparison of signals recorded by the two methods simultaneously (Fig. 1) indicates that the patch electrode signal is a derivative of the membrane potential. When the membrane potential is constant, current recorded by 


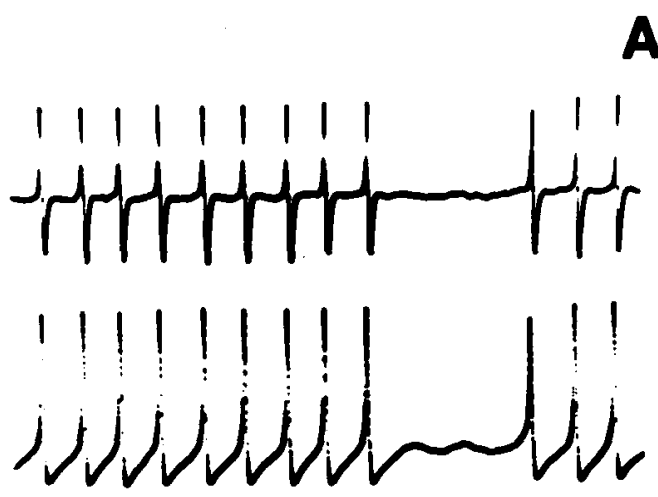

\section{Spikes}

\section{EPSPs}

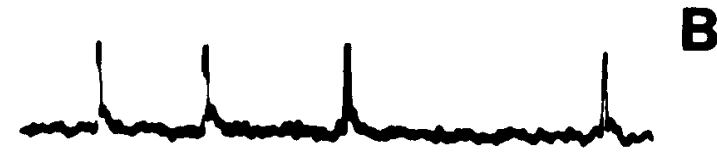

\section{IPSPs}

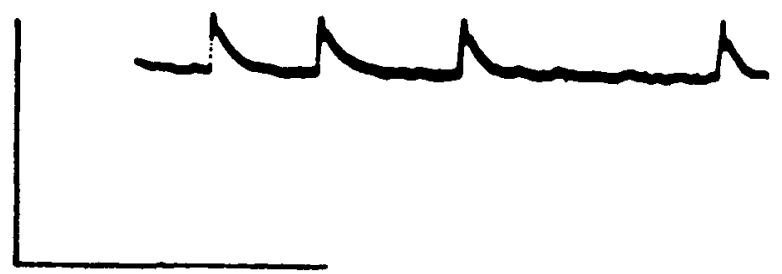

Figure 1. A comparison of simultaneous patch electrode recordings and intracellular voltage recordings from the same cell in cultures which are more than 30 days old. For all traces, the horizontal bar is $100 \mathrm{msec}$. The upper traces in each comparison are patch electrode recordings and the lower traces are intracellular voltage. A, Action potentials. Vertical scale, $400 \mathrm{pA}$ (top) or $80 \mathrm{mV}$ (bottom). $B$, EPSPs. Vertical scale, $160 \mathrm{pA}($ top $)$ or $80 \mathrm{mV}$ (bottom). C, IPSPs. Vertical scale, $160 \mathrm{pA}($ top) or $80 \mathrm{mV}$ (bottom).

the patch electrode changes as the conductance of the patch of membrane changes. Such currents are generated by ionic channels in the membrane patch and are relatively small. When the membrane potential changes, the patch of membrane passes a current which is determined by its complex impedance. The passive resistance of the membrane patch gives rise to a signal that is proportional to the membrane potential, and the capacitance of the membrane patch gives rise to a signal that is proportional to the derivative of the membrane potential. Examination of Figure 1 indicates that the bulk of the current measured by the patch electrode during an action potential flows through the patch capacitance. Other considerations, including computations of resistive and capacitive patch currents, support this interpretation $(H$. Lecar, M. B. Jackson, and B. S. Wong, unpublished observations).

When the intracellular electrode used for simultaneous 
recording contained a $\mathrm{KCl}$ solution rather than a potassium acetate solution, all synaptic potentials were upward as though they were excitatory. When the patch electrode recording was established first, hyperpolarizing IPSPs often were identified, but following impalement with a $\mathrm{KCl}$ electrode, all synaptic events became positive. This reversal of IPSP polarity is caused by the KCl-filled microelectrode, which produces an increase in the intracellular chloride content (Barker and Ransom, 1977).

The cultures contain both spinal cord cells and dorsal root ganglion cells (Ransom et al., 1977). In attempts to record from dorsal root ganglion cells with a patch electrode, we observed no spontaneous electrical activity, reaffirming previous reports that these cells are quiescent (Ransom et al., 1977).

Variation in activity with cell size. Figure 2 shows how the percentage of spinal cord cells with EPSPs, IPSPs, and action potentials varies with cell size. The decision to divide the cells into age groups (9 to 21 and 29 to 51 days) was based on observed variations in activity with culture age (next section). With younger cultures, cells larger than $20 \mu \mathrm{m}$ were not common as is reflected by the small sample size of large cells in Figure $2 A$. Cells larger than $10 \mu \mathrm{m}$ were very active and there was no significant variation in activity of any kind with cell size. Activity in cells with diameters of less than 10 $\mu \mathrm{m}$ was rare. In particular, IPSPs were never observed, and cells with EPSPs and action potentials were also uncommon. The level of activity in these small cells was identical in the two age groups.

Figure $3 B$ is an example of a recording made from a 7 $\mu \mathrm{m}$ cell in a 4-day-old culture. When activity was seen in cells smaller than $10 \mu \mathrm{m}$, the events were usually much less frequent than is characteristic for larger cells. Stable recordings from small cells could be readily obtained although cell damage was somewhat more common. Damage was evident either as a visual loss of phase brightness, as large noisy electrical signals, or both; damage usually resulted when the electrode crushed the cell against the bottom of the culture dish. Cells showing any evidence of damage during the recording were not counted in the tabulations. The possibility that the patch electrode is an ineffective means of recording from such small cells is difficult to test, but size does not appear to be a serious obstacle since we were able to record activity from minute threadlike axons of very small diameter.

Variation with culture age. Recordings from spinal cord cells in cultures of varying age are shown in Figure 3. All of the traces shown are representative except the first one (Fig. $3 A$ ). Figure $3 A$ shows an action potential recorded from a cell 1 day after the culture was plated. Action potentials and other forms of electrical activity were infrequent at this early stage. Figure 4 shows phase contrast micrographs of cultures at various stages to
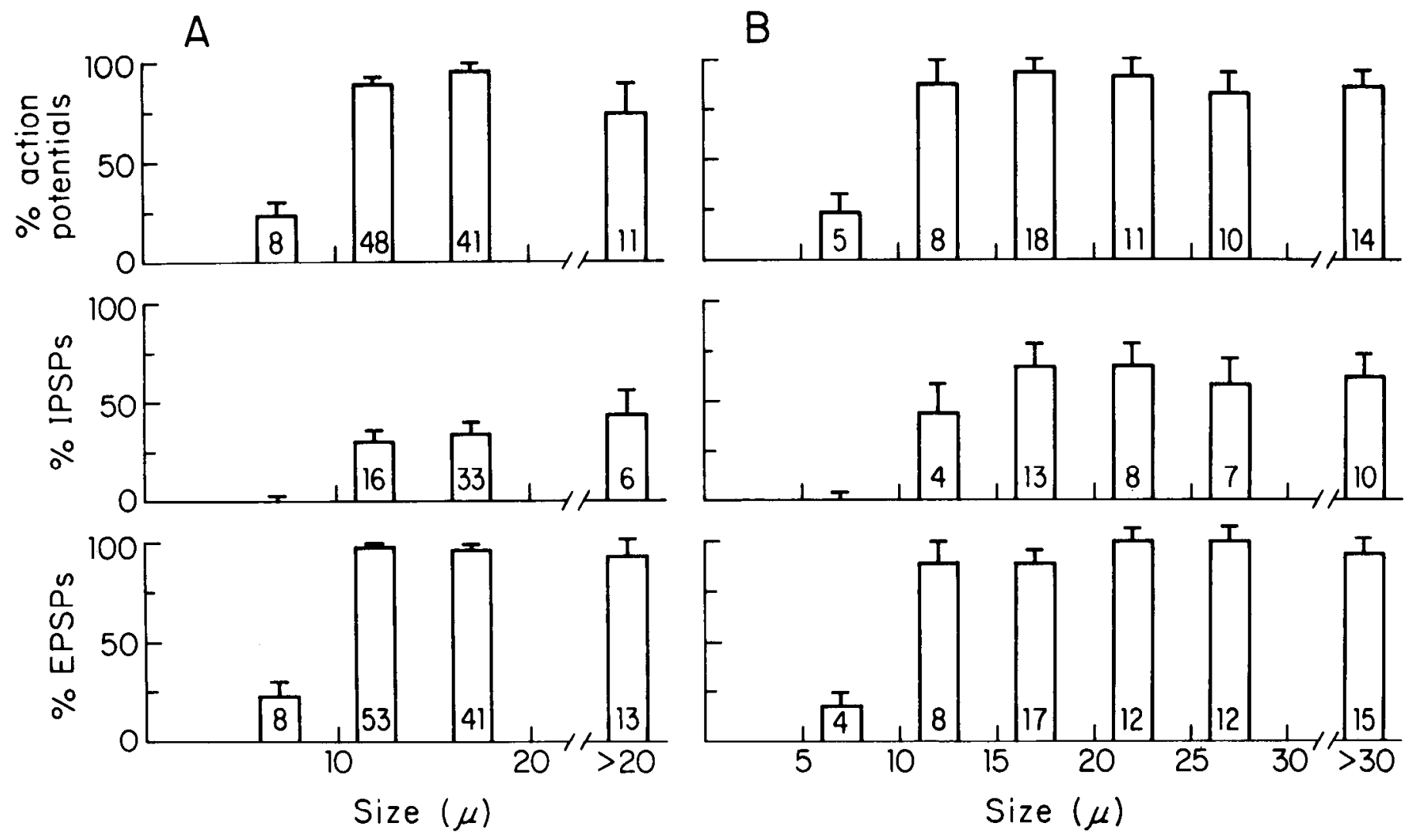

Figure 2. Histograms displaying the dependence on cell size of the proportion of cells with various forms of spontaneous electrical activity. The numbers in the bars are the number of cells found displaying the type of event counted. The error bars are estimated standard deviations computed from the number of trials, $N$, and the number of successes, $m$, by using the expression $(N+1-m)(m+1) /(N+2)^{2}(N+3)$. This follows from the Baye's formula method of estimating probabilities from repeated trials. $A$, Younger cells ( 9 to 21 days in culture); $B$, older cells (29 to 51 days in culture). 

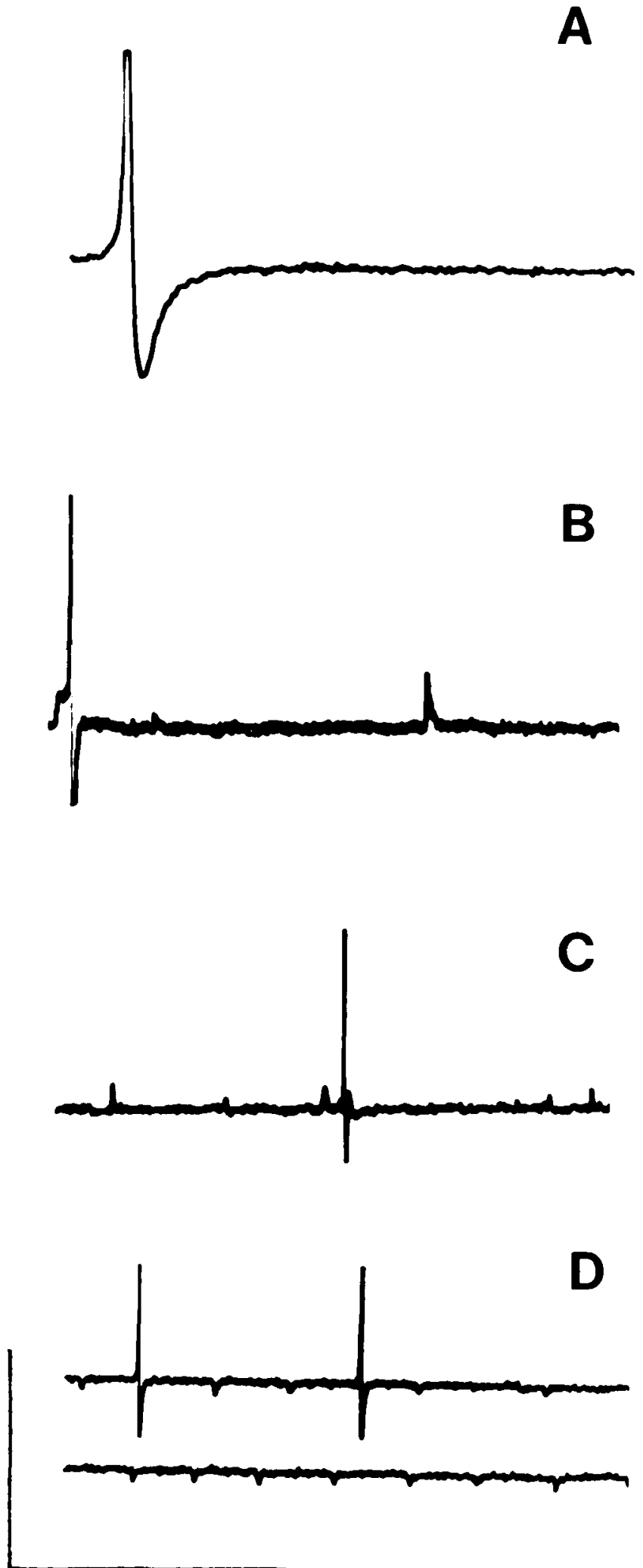

Figure 3. Examples of spontaneous electrical events in cells from cultures of different ages. The vertical scale is $160 \mathrm{pA}$ for all traces. $A$, Action potential in a $15-\mu \mathrm{m}$ cell from a 1-day-old culture. Horizontal scale, 25 msec. $B$, Action potential and EPSP in a $7-\mu \mathrm{m}$ cell from a 4 -day-old culture. Horizontal scale, $-100 \mathrm{msec}$ in traces $B, C$, and $D$. C, Action potential and EPSPs in a $15-\mu \mathrm{m}$ cell from a 13 -day-old culture. $D$, Action potentials and IPSPs in a 15- $\mu \mathrm{m}$ cell from a 39-day-old culture. indicate the degree of morphological development. After only 4 days in culture, the cells are small, typically about $10 \mu \mathrm{m}$, but appear to have developed some processes. After 15 days in culture, cells have elaborate processes but are still small. Thirty-five-day-old cultures have a broad dispersion of cell sizes (Fig. $4 D$ ) and very elaborate processes.

The pooled electrophysiological results from 32 experiments on cultures from seven different dissections are presented in Figure 5. Each point in this figure represents at least 3 experiments on cultures from as many different dissections. Since cells smaller than $10 \mu \mathrm{m}$ were different and generally inactive, they were not included in this figure. A number of notable variations in the activity of cultures with age are evident. (1) Immediately following the dissection, activity is present at a very low level. There is a dramatic increase during the first 2 weeks, with almost every cell showing spontaneous activity by the end of 10 days in culture. (2) Whereas the number of cells with EPSPs and action potentials reaches a maximum early, the number of cells with IPSPs increases slowly over the entire period of culture. The contrast between IPSPs in young and old cultures is also evident in Figure 2 (compare any size group for IPSPs in Fig. 2, $A$ and $B$ ), but Figure 5 reveals the gradual increase in this type of activity. (3) There is a marked transient depression in the level of spontaneous EPSP and action potential activity late in the 4 th week of culture which rapidly recovers. This depression extends well beyond the uncertainty estimates indicated by the error bars of the figure and is statistically significant. (4) There are almost always slightly fewer cells with action potentials than with EPSPs. The difference between two points at one particular age would not be significant, but this difference is seen consistently for all ages other than 1 day old.

Tetrodotoxin-induced depression of CAT activity. In order to assess the time course of neuronal vulnerability to electrical blockade, $1 \mu \mathrm{M}$ TTX was applied to the cultures at various intervals after plating and the CAT activity of control and treated cultures was compared. In control cultures, CAT activity increased during the first 2 weeks (Giller et al., 1977) with roughly the same time course as the development of EPSPs and action potentials. Control experiments in cultures that were more than 2 weeks old produced CAT activities of $100 \mathrm{pmol} /$ $\mathrm{min} /$ culture.

A summary of the effects of TTX on CAT activity is shown in Figure 6. Application of TTX early in development (days 1 to 4 and 3 to 6 ) produced no significant changes from control cultures. This period of insensitivity corresponds to a developmental period during which $50 \%$ or more of the cells were found not to be spontaneously active. In contrast, cells exposed to TTX from 4 to 7 days after plating had CAT activities that were only $65 \%$ of control levels $(p<0.001)$. Since the total duration of exposure to TTX was the same as for the earlier intervals, the degree of depression of CAT activity can be attributed to the developmental age of the culture.

CAT activity measured in cultures exposed to TTX from 1 to 7 days after plating was not significantly different from that obtained following a 4- to 7-day 

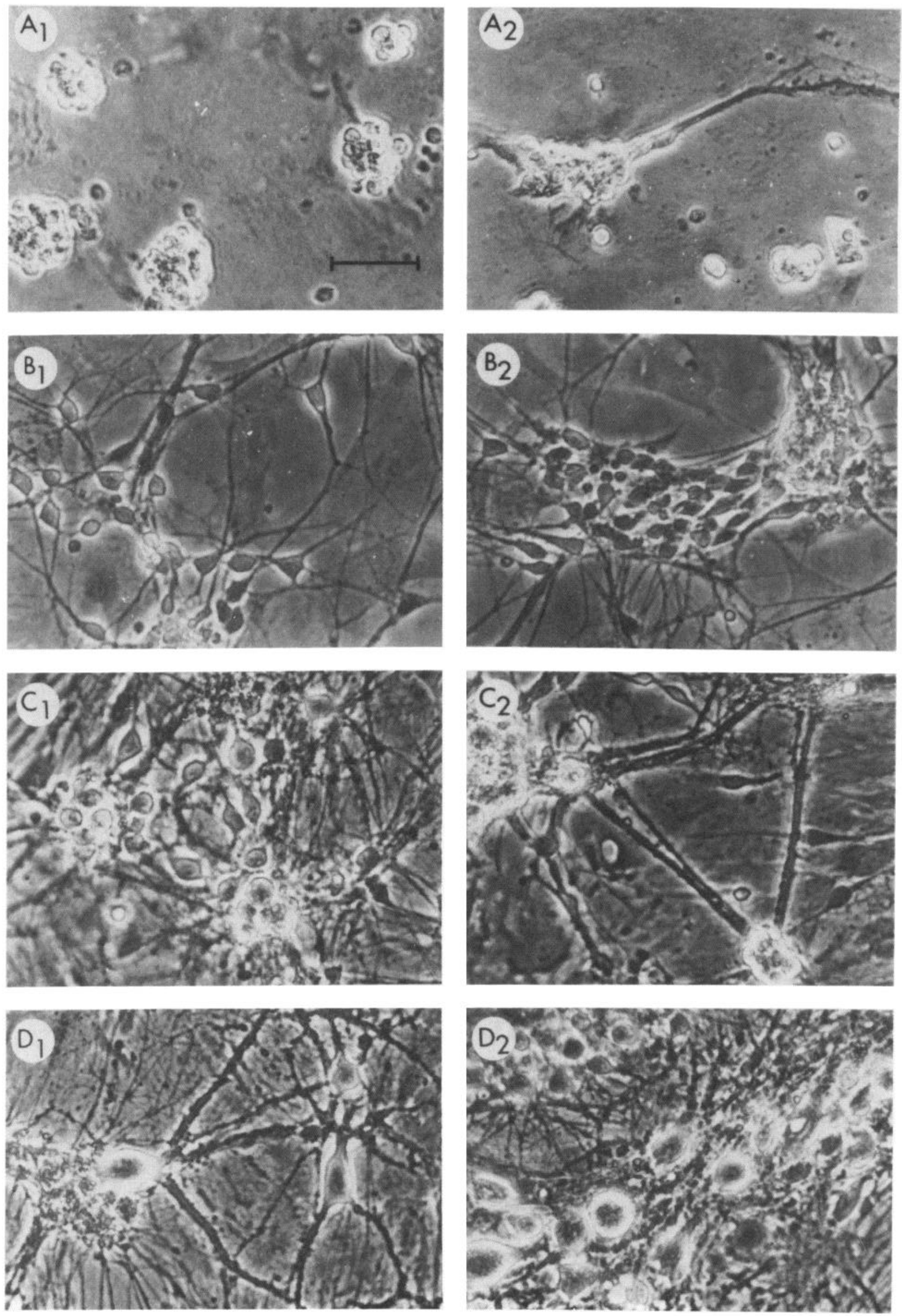

Figure 4. Phase contrast photomicrographs of cultures at various ages after plating. For each age, two representative pictures are shown. Gradual increases in cell body size and number of processes can be seen. Calibration bar, $50 \mu \mathrm{m}$. The ages of the cultures are: $A 1$ and $A 2,1$ day; $B 1$ and $B 2,4$ days; $C 1$ and $C 2,15$ days; $D 1$ and $D 2,37$ days. 


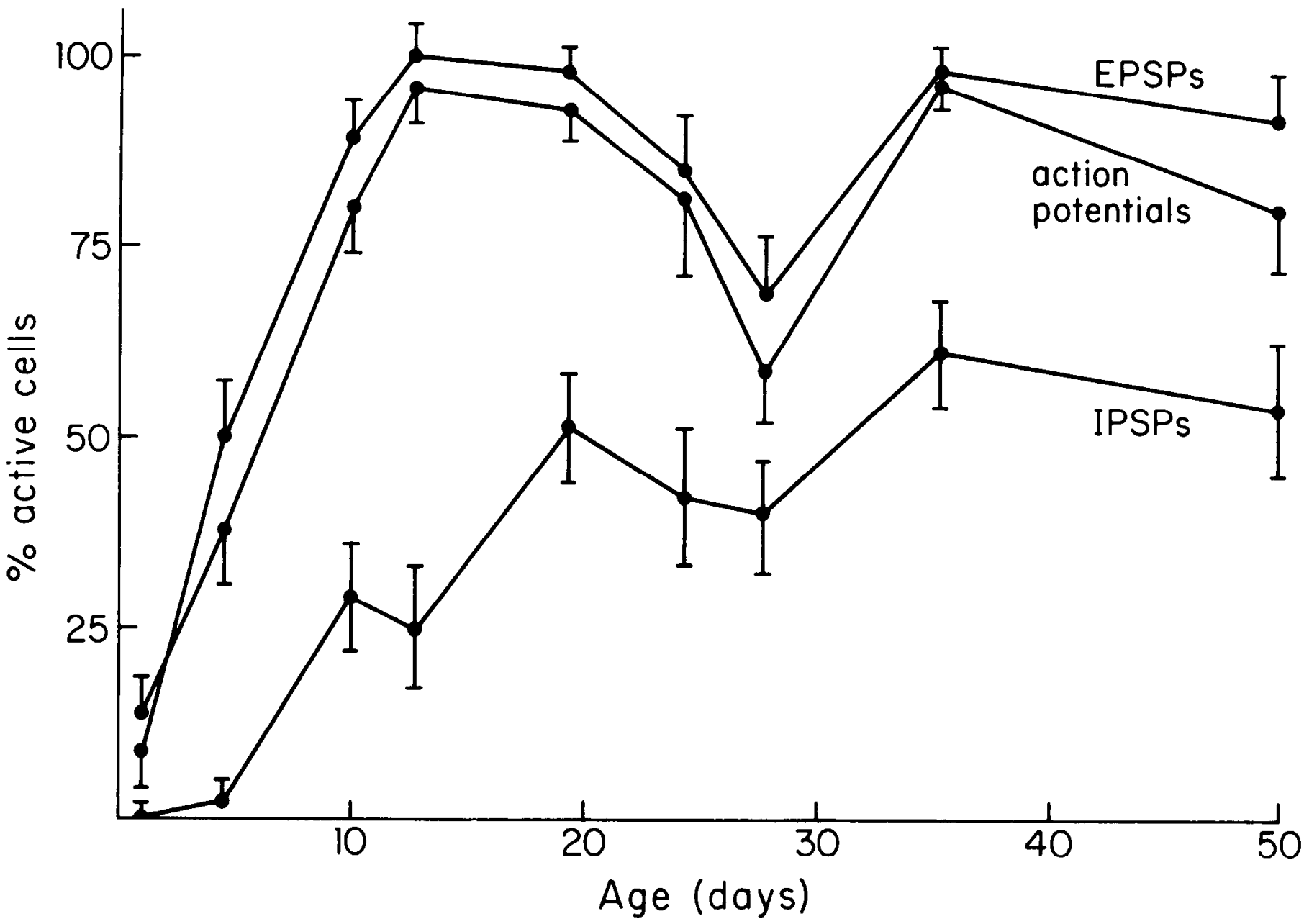

Figure 5. Variation in the proportion of cells with various forms of spontaneous activity with the age of the culture. The cells from which we recorded to obtain this data were all $10 \mu \mathrm{m}$ or larger. The error bars are estimated standard deviations as in Figure 2.

treatment, providing another indication that the timing of exposure is critical. Decreases in CAT activity also were observed during the 2nd, 3rd, and 4th week in culture. One-week pulses of TTX applied to cultures throughout the 1-month testing period reduced activities by 23 to $27 \mathrm{pmol} / \mathrm{min} /$ culture as compared with controls. More chronic exposure resulted in greater decreases in CAT activity. TTX exposure for the first 3 weeks in culture produced the largest observed decrease, depressing activity by $60 \mathrm{pmol} / \mathrm{min} /$ culture as compared with controls.

The development of sensitivity to inhibitory compounds. The slow development of IPSPs motivated our examination of the effect of the putative inhibitory transmitters glycine and GABA on the electrical activity of these cultures. Acute application of $0.4 \mathrm{~mm}$ GABA to mature spinal cord cultures has been shown to block all ongoing electrical activity (Nelson et al., 1977). Both glycine and GABA eliminate activity in spinal explants (Crain, 1972). After examining several cells in a culture, glycine or GABA was added to a final concentration of $0.4 \mathrm{~mm}$, and following this addition, more cells were examined. GABA was effective in completely blocking activity at all ages tested (Fig. $7 \mathrm{C}$ ). Single action poten- tials were observed in only 2 out of 33 cells in the presence of GABA, with cultures ranging in age from 9 to 45 days old. Application of glycine to young cultures did not eliminate ongoing activity (Fig. $7, A$ and $B$ ). Following glycine addition to three cultures between 9 and 14 days old, 14 out of 31 cells spontaneously produced action potentials. In two older cultures ( 35 and 45 days old) to which glycine had been added, only one action potential was seen from a total of 15 cells. In a 21-day-old culture, activity was greatly reduced but not completely abolished by glycine (Fig. $7 D$ ). All cultures had abundant spontaneous electrical activity before these inhibitory agents were added.

The bath application of these compounds indicates that GABA sensitivity develops very early and persists, whereas sensitivity to glycine increases gradually with the age of the culture.

\section{Discussion}

Since the patch electrode recording is obtained without penetration of the cell membrane, there is good reason to believe that it is a less invasive probe than the microelectrode for recording ongoing electrical activity. It is still arguable that mechanical disturbance results from 


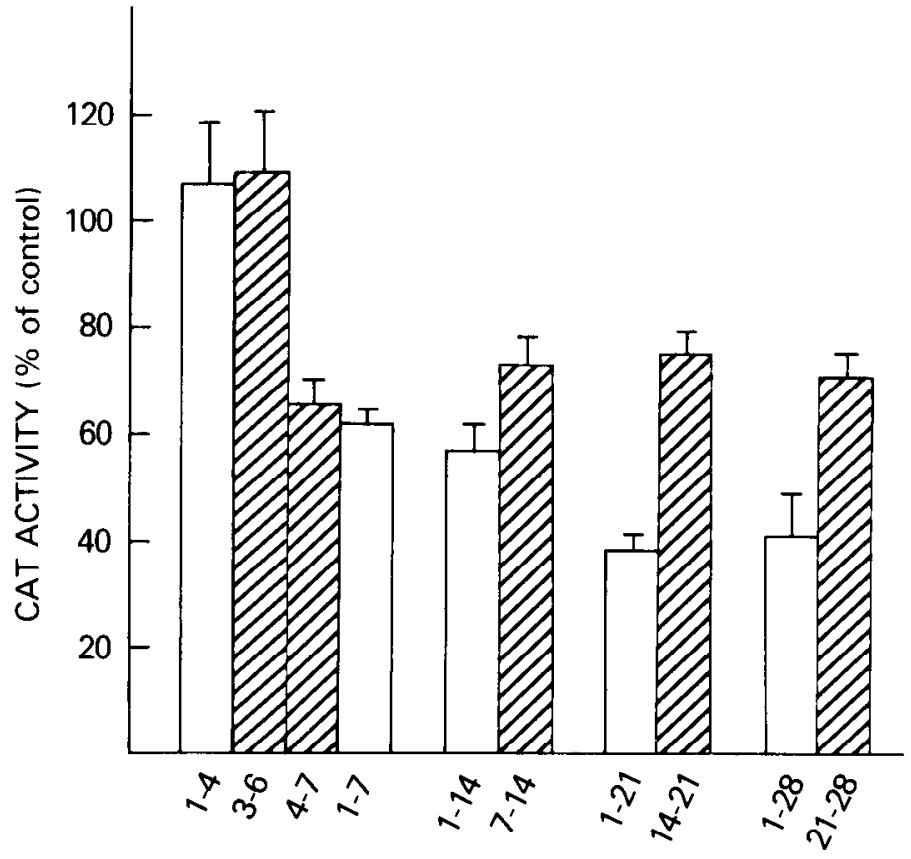

DAYS OF TTX EXPOSURE

Figure 6. Choline acetyltransferase activity in spinal cord dorsal root ganglia cultures after exposure to TTX at various intervals after plating. The open and hatched bars contrast continuous TTX treatment with a period of treatment beginning after cultures were established. Activity was measured during $10-\mathrm{min}$ incubations at $37^{\circ} \mathrm{C}$. The results are expressed as the percentage of untreated sister cultures. Each value is the mean \pm SEM of four determinations. The TTX concentration was $1 \mu \mathrm{M}$.

electrode-membrane contact or from deforming the cell membrane, and these doubts will be difficult to overcome with complete satisfaction. Nevertheless, with the patch electrode, it is now possible to subject a wider range of cell sizes and a broader range of culture ages to electrophysiological scrutiny.

The consistently high proportion of EPSPs and action potentials among cells as small as 10 to $14 \mu \mathrm{m}$ illustrates the effectiveness of recording from small cells. Uniformity in the nature of electrical activity for cell sizes down to 10 to $14 \mu \mathrm{m}$ suggests that, with regard to basic electrical excitability, these neurons are homogenous. However, without quantitative studies of the frequency of events in individual cells and detailed characterization of membrane properties, we cannot rule out more subtle systematic variations in electrophysiological properties with cell size.

Figure 7. The effect of acute glycine or GABA application on spontaneous activity. A, First trace, a recording of activity in a cell from a 14-day-old culture before glycine addition; second trace, recording from the same cell shortly after the addition of glycine. $B$, Another cell from the same culture in which $A$ was recorded following glycine addition. $C$, First trace, before GABA addition (9-day-old culture); second and third traces, recordings from the same cell after GABA addition. $D$, First trace, before glycine addition (21-day-old culture); second and third traces, recordings from the same cell after glycine addition. Vertical scale, $160 \mathrm{pA}$ for $A$ and $B$ and $400 \mathrm{pA}$ for $C$ and $D$. Horizontal scale, $100 \mathrm{msec}$ for all traces.
Within 1 day after plating, a few cells in the culture are found to display action potentials and EPSPs. The proportion of cells exhibiting this spontaneous activity increases dramatically during the 1st week. This could represent a recovery from the trauma of dissociation; however, neural development and synaptogenesis are
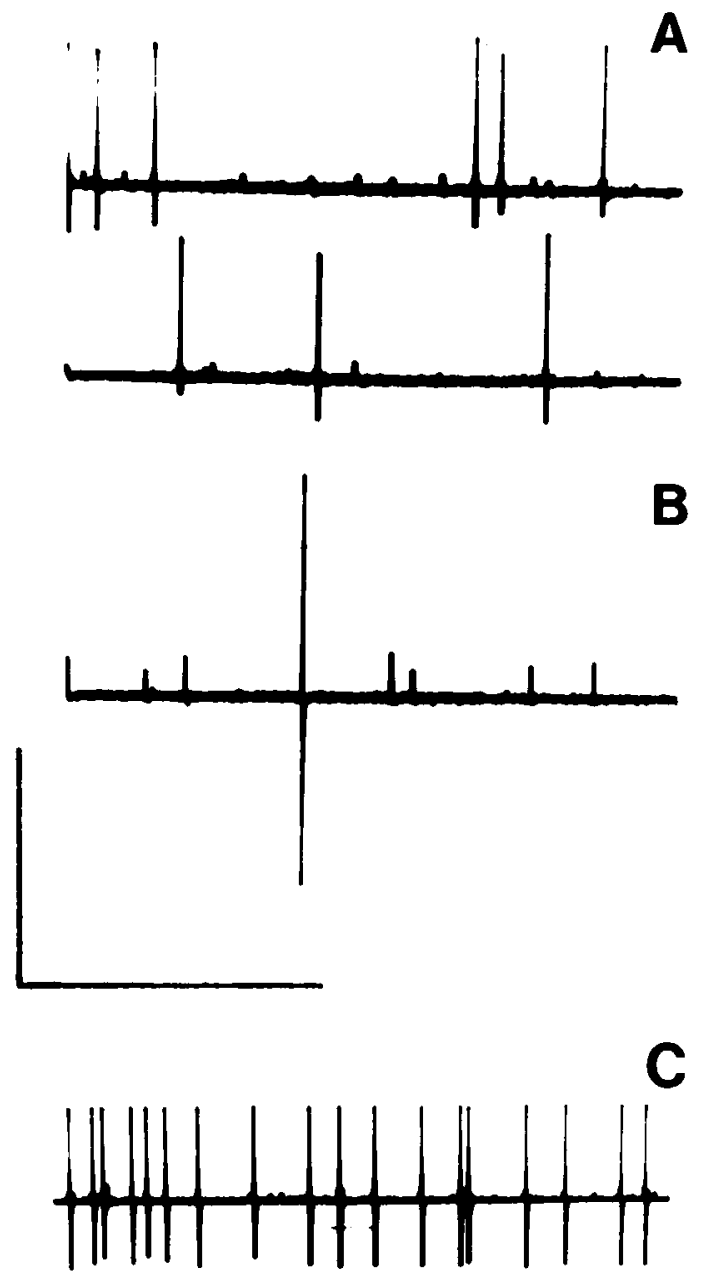

D

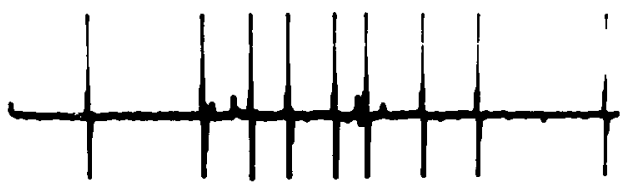


vigorous during and immediately following the period in utero when the embryos are removed to prepare these cultures (Vaughn et al., 1977). Spontaneous neural activity in very young rodent spinal-muscle co-cultures was demonstrated indirectly by recording EPSPs in the muscle cells (Obata, 1977). Spontaneous activity in mouse spinal explants was seen after culturing for only 6 days (Corner and Crain, 1972). Even more precocious prenatal electrical activity is found in the chick embryonic spinal cord (Bekoff, 1981).

The first report that electrical activity is essential to neuronal development in this culture system (Bergey et al., 1978) was based on visual counts of the number of large cells. Subsequent studies demonstrated that the addition of TTX to the culture medium could depress CAT activity as well (Bergey et al., 1981a). The early loss of this neuron-specific marker is followed by the death of neurons of all sizes (D. Brenneman, E. Neale, W. H. Habig, and P. G. Nelson, manuscript in preparation). Thus, the assay of CAT activity is a useful method for detecting the onset of TTX-induced spinal neuron demise, and since it takes a few days for neurons to die and disintegrate, CAT activity is especially useful for high resolution studies of the time course of sensitivity to electrical blockade.

The early increase in the spontaneous electrical activity of these cultures is accompanied by an increase in the sensitivity of CAT activity to the depression of electrical activity. During the time when tetrodotoxin has its greatest impact, essentially every cell has action potentials and EPSPs. One- to 4-day-old cells exhibited low levels of spontaneous activity and showed no depression of CAT activity after exposure to TTX. The sensitivity of CAT activity to TTX follows a developmental time course generally similar to the appearance of spontaneous action potentials and EPSPs. The survival and normal development of spinal neurons under control conditions, without TTX, suggests that a critical level of spontaneous electrical activity is reached before or coincident with the appearance of the requirement for electrical activity.

Abundant electrical activity in spinal cord cells during the time when TTX has its maximal effect and the absence of activity in the dorsal root ganglion cells of young cultures strengthens the argument that electrical activity promotes the survival of spinal cord neurons in cell culture (Bergey et al., 1981a). The sequential appearance of EPSPs followed by IPSPs, with fewer cells in young cultures receiving inhibitory synaptic inputs, may be important in permitting the high level of electrical activity necessary for spinal neuron survival. This slower development of IPSPs also may be responsible for the shortening of phasic bursts and cycles seen in spinal explants (Tarrade and Crain, 1978). Recordings from the caudate of the kitten demonstrate that EPSPs develop before IPSPs (Morris et al., 1979). A recent study of electrophysiological development in the rabbit hippocampus reveals a similar sequence in the development of excitatory and inhibitory synapses (Schwartzkroin, 1981). It should be interesting to learn whether there is a general trend that inhibitory synapses develop later in nerve tissue with an early critical stage in which a requirement for electrical activity is exhibited.
An attempt was made to probe the development of synaptic activity in greater detail. An examination of the development of chemosensitivity was conducted by recording spontaneous activity following the addition of putative inhibitory transmitters to the bathing medium. An increase in the effectiveness with which glycine abolished spontaneous activity paralleled the development of inhibitory synaptic activity. This roughly simultaneous development adds support to the proposal that glycine is the neurotransmitter of the majority of the inhibitory synapses in this preparation (Nelson et al., 1977). The appearance of muscarinic binding sites and kainic acid sensitivity in the same culture system follows a similar time course (Brookes and Burt, 1980). It will be important for future research to address the question of whether there is coordination in the development of these various processes.

GABA was completely effective in blocking activity in cultures of different ages, including young cultures which had few cells exhibiting IPSPs but many cells exhibiting action potentials and EPSPs. This early GABA sensitivity appears to be nonsynaptic. It could be tonic or extrajunctional as suggested by Crain and Bornstein (1974) or it could be presynaptic (Nelson et al., 1977). Since barbiturates can interact with the GABA response of cultured spinal neurons (Macdonald and Barker, 1978), the demonstration of an early sensitivity to GABA eventually may become part of an explanation for the adverse effects of phenobarbital on spinal cord cell cultures (Bergey et al., 1981b).

The sensitivity of spinal neurons to electrical blockade is a developmentally transient phenomenon since TTX application at later times in culture has a progressively weaker effect (Bergey et al., 1981a), while spontaneous activity continues. The brief decrease in electrical activity seen at the end of the 4th week of culture occurs at about the time that the effects of TTX first begin to diminish. This dip seen in Figure 5 may represent a pause between periods when different generators of electrical activity are in control. Linking this observation to the development of IPSPs, or to muscarinic receptors (Brookes and Burt, 1980), is another intriguing possibility.

The complex developmental processes which take place in spinal cord cell cultures can be studied by a variety of techniques, and it is advantageous to monitor the progress of several forms of neuronal activity in parallel. Such an approach has the potential to bring out interesting relations and forms of interdependence between different elements of a developing system. In the development of neurons, the electrical properties constitute a functional manifestation, giving rise to electrical activity which then acts as a force to guide development further.

\section{References}

Barker, J. L., and B. R. Ransom (1977) Amino acid pharmacology of mammalian central neurones grown in tissue culture. J. Physiol. (Lond.) 280: 331-354.

Bekoff, A. (1981) Embryonic development of chick motor behavior. Trends Neurosci. 4: 181-184.

Bergey, G. K., R. L. Macdonald, and P. G. Nelson (1978) Adverse effects of tetrodotoxin on development and survival of postsynaptic cells in tissue culture. Soc. Neurosci. Abstr. 
4: 601 .

Bergey, G. K., S. C. Fitzgerald, B. K. Schrier, and P. G. Nelson (1981a) Neuronal maturation in mammalian cell culture is dependent on spontaneous electrical activity. Brain Res. 207: 49-58.

Bergey, G. K., K. F. Swaiman, B. K. Schrier, S. Fitzgerald, and P. G. Nelson (1981b) Adverse effects of phenobarbital on morphological and biochemical development of fetal mouse spinal cord neurons in culture. Ann Neurol 9: 584-589.

Brookes, N., and D. R. Burt (1980) Development of muscarinic receptor binding in spinal cord cell cultures and its reduction by glutamic and kainic acids. Dev. Neurosci. 3: 118-127.

Corner, M. A., and S. M. Crain (1972) Patterns of spontaneous bioelectric activity during maturation in culture of fetal rodent medulla and spinal cord tissues. J. Neurobiol. 3: 25-45.

Crain, S. M. (1972) Depression of complex bioelectric activity of mouse spinal cord explants by glycine and $\gamma$-amino butyric acid. In Vitro 7: 249.

Crain, S. M., and M. R. Bornstein (1974) Early onset of inhibitory functions during synaptogenesis in fetal mouse brain cultures. Brain Res. 68: 351-357.

Giller, E. L., J. H. Neale, P. N. Bullock, B. K. Schrier, and P. G. Nelson (1977) Choline acetyltransferase activity of spinal cord cell cultures increased by co-culture with muscle and muscle conditioned medium. J. Cell Biol. 74: 16-29.

Godfrey, E. W., B. K. Schrier, and P. G. Nelson (1980) Source and target cell specificities of a conditioned medium factor that increases choline acetyltransferase activity in cultured spinal cord cells. Dev. Biol. 77: 403-418.

Hamill, O. P., A. Marty, E. Neher, B. Sakmann, and F. J. Sigworth (1981) Improved patch-clamp techniques for highresolution current recording from cells and cell-free membrane patches. Pfluegers Arch. 391: 85-100.

Jackson, M. B., and H. Lecar (1979) Single post-synaptic channel currents in tissue cultured muscle. Nature 282: 863-864.

Jackson, M. B., H. Lecar, D. A. Mathers, and J. L. Barker (1982) Single channel currents activated by $\gamma$-aminobutyric acid, muscimol, and (-)-pentobarbital in cultured mouse spinal neurons. J. Neurosci. 2: 889-894.

Macdonald, R. L., and J. L. Barker (1978) Different actions of anticonvulsant and anesthetic barbiturates revealed by use of cultured mammalian neurons. Science 200: 775-777.

Morris, R., M. S. Levine, E. Cherubini, N. A. Buchwald, and C. D. Hull (1979) Intracellular analysis of the development of responses of caudate neurons to stimulation of the cortex, thalamus, and substantia nigra in the kitten. Brain Res. 173: 471-487.

Neher, E., B. Sakmann, and J. H. Steinbach (1978) The extracellular patch clamp: A method for resolving currents through individual open channels in biological membranes. Pfluegers Arch. 375: 219-228.

Nelson, D. J., and F. Sachs (1979) Single ionic channels observed in tissue-cultured muscle. Nature 282: 861-863.

Nelson, P. G., B. R. Ransom, M. Henkart, and P. N. Bullock (1977) Mouse spinal cord in cell culture. IV. Modulation of inhibitory synaptic function. J. Neurophysiol. 40: 1178-1187.

Obata, K. (1977) Development of neuromuscular transmission in culture with a variety of neurons and in the presence of cholinergic substances and tetrodotoxin. Brain Res. 119: 141153.

Ransom, B. R., E. Neale, M. Henkart, P. N. Bullock, and P. G. Nelson (1977) Mouse spinal cord cells in culture. I. Morphology and intrinsic neuronal electrophysiological properties. J. Neurophysiol. 40: 1132-1150.

Schrier, B. K., S. H. Wilson, and M. Nirenberg (1974) Cultured cell systems and methods for neurobiology. Methods Enzymol. 32: 765-789.

Schwartzkroin, P. A. (1981) Development of rabbit hippocampus: Physiology. Dev. Brain Res. 1: 469-486.

Tarrade, T., and S. M. Crain (1978) Regional spontaneous discharges during maturation in culture of fetal mouse medulla and spinal cord explants. Dev. Neurosci. 1: 119-132.

Vaughn, J. E., T. Sims, and M. Nakashima (1977) A comparison of the early development of axodendritic and axosomatic synapses upon embryonic mouse spinal motor neurons. J. Comp. Neurol. 175: 79-100. 